principal agenda-making body for the everyday conversation of the ordinary man or woman, and therefore for that elusive element called public opinion. From that point of view alone, the broadsheet deserves the attention of those scientific workers who are interested in the shaping of public opinion and the encouragement of a scientific outlook or approach to the many social problems in which scientific and technical factors are involved.

\section{The Conception of Curved Space}

Is a paper read at a meeting of the Victoria Institute, London, on April 4, entitled "Fallacies underlying the Einstein-Eddington Conception of Curved Space", Mr. Albert Eagle declared that "the whole conception does such violence to the nature of our minds that we can only call it a lie. . . ." $\mathrm{He}$ admitted that a disk might change its dimensions in a gravitational field, and so be distorted, but this should be regarded as a distortion of matter, not of space. The relativity formula for the distance between two points in a gravitational field might be correct if applied to the measurements taken with a material measuring rod, but such measurements should not be taken as the space of external reality. Mr. Eagle regarded the idea of curved space as selfcontradictory, chiefly on psychological grounds. Moreover, he deprecated the attempt to abstract from reality everything that is tangible, and the attempt to reduce the physical universe to a purely geometrical universe. He complained that "practically no editor will publish an article making an attack on the theory". Quite apart from the difficulty under which most editors labour of finding space for the many contributions submitted, it may be suggested that a partial explanation may be, in $\mathbf{M r}$. Eagle's own words, that "Some people may think that I have more moral indignation, perhaps amounting even to animosity, against the theory of curved space than can be justified against any mere theory, no matter how erroneous or misleading it is."

\section{Discovery}

Wry the April issue our contemporary, Discovery, enters upon a new phase of its existence. It appears in new format, an octavo size, approximately that of a popular magazine, instead of a quarto ; and it is now published by the Cambridge University Press. Discovery, since its foundation soon after the Great War, with Sir J. J. Thom on, Sir Frederic Kenyon and the late Prof. R. S. Conway as its trustees, has consistently maintained a high standard of accuracy and a uniform distinction in style in bringing before an educated, but non-technical, public, information relating to the latest advances in knowledge and scientific discovery. Originally published by the house of John Murray, it was transferred to Messrs. Benn Bros. in 1924, by whom it has been published since that date until March of the current year, when responsibility for its future production was accepted by the Syndics of the Cambridge University Press. Dr. C. P. Snow, of Christ's College, Cambridge, will act as editor. Although the form of publication is changed, there will be no break in policy, which under the general supervision of the Committee representing the Trustees will be to continue to place before its readers, so far as possible, an accurate and universal view of advance, not only in physics, astronomy, biochemistry and medicine, but also in archæology, travel, architecture and the like in terms and phrasing of general appeal. The first issue in the new form holds out every hope of the fullest attainment of this aim. Among the contributors are Sir James Jeans, who writes on "The Origin of the Planets", and Dr. L. Infeld, a pupil of and col. laborator with Prof. Einstein, on "Holes in Empty Space", while Mr. R. Philmore and Dr. J. Judkin contribute an amusing inquest on the scientific aspects of methods of murder in detective fiction. An article on new developments in colour photo. graphy is illustrated by a colour plate taken on the New Agfacolour film. We wish the new editor and publishers every success in their endeavour to enlarge popular interest in the progress of science.

\section{Social Background of the Rise of Science}

THE sixth lecture of the series "Science in the Social World" organized by the Left Book Club Scientists' Group was delivered on March 28 by Prof. P. M. S. Blackett, his subject being "The Social Background of the Rise of Science in the Seventeenth Century". Prof. Blackett contrasted the view that the rather sudden rise of modern science in the seventeenth century was largely a matter of chance, with the view that this rise was closely related to the technical needs of the time. In particular, the progress of navigation and mining in the fifteenth and sixteenth centuries had led to a very urgent demand for the solution of certain scientific problems. The importance attached to these problems is shown by the efforts made to solve them. For example, at the end of the fifteenth century, eighty-three astronomers were employed in Lisbon on problems connected mainly with navigation, and by the end of the sixteenth century large financial rewards in the shape of prizes were offered for the solution of the problem of longitude. Again, Agricola in his book "De Re Metallica", published in 1556 , listed sixteen different ways of pumping mines clear of water, a clear sign that no one of them was really satisfactory. It is interesting to note that the use of a clock at sea as a way of finding longitude was suggested so early as 1530 , but that it was not until 1764 that this method was successfully used. Many of the scientific problems solved by Newton and his contemporaries had been raised into prominence between one and two hundred years before by the demand of practical techniques. The technical progress in the Middle Ages was not only an important contributory cause of the rise of moderm science, but also led to a political struggle between the monarchy and feudal aristocracy against the rising merchant and business class. In England the struggle had been won by the latter by the time of the founding of the Royal Society, and this fact undoubtedly contributed to the rapidity with which science and technique developed in England. 